\title{
INTRODUCTION
}

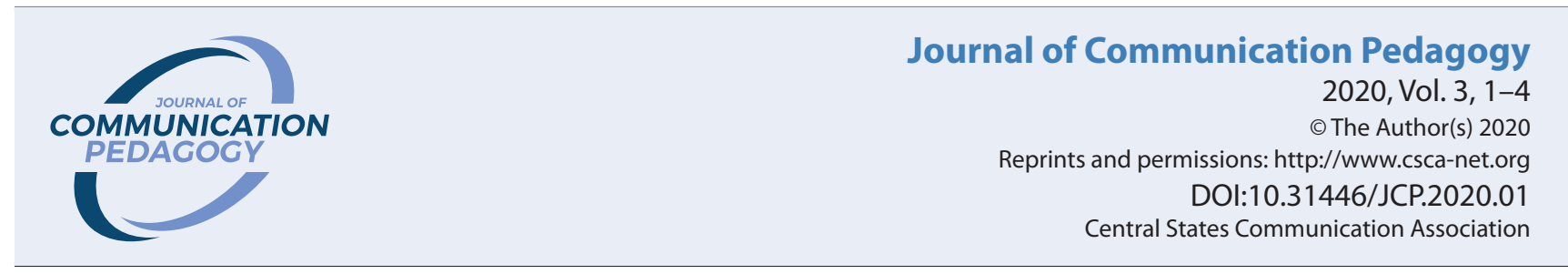

\section{Editor's Note to Volume 3 of the Journal of Communication Pedagogy}

\section{Where do we go from here?}

\author{
Deanna D. Sellnow 주
}

Nonviolent anti-apartheid activist and Nobel Peace Prize winner, Nelson Mandela, is credited with saying "education is the most powerful weapon which you can use to change the world." I agree. In fact, I accepted the responsibility of doing the important work of serving as editor of the Journal of Communication Pedagogy in large part because I agree. To clarify, I believe this journal can serve as a vehicle to empower its readers to use instructional communication and research to change the world in powerfully positive ways. For these reasons, I sincerely thank members of the Central States Communication Association for entrusting me to serve. As a preface to this first issue in my tenure as editor, I would like to set the stage by introducing you to my editorial philosophy as an instructional communication teacher-scholar. My philosophy is essentially grounded in three core beliefs:

1. Instructional communication does not occur only in traditional classroom settings (and, in fact, may even be more influential when it occurs outside that box).

2. We do our best work to change the world when we work together synergistically (that is, we are more powerful as teams than as individuals).

3. As teacher-scholars, it is our responsibility to encourage, mentor, and create opportunities for rising stars.

The following paragraphs unpack these three tenets as I have tried to operationalize them in the editorial processes employed and in the manuscripts included.

For some reason, all too often, people mistakenly believe that communication pedagogy, communication education, and instructional communication are what occurs between teacher and students in a formal 
classroom context. I argue they are only partially correct because they also occur beyond the walls (albeit literal or virtual) walls of formal classrooms. We engage in both the teaching and learning of communication concepts and skills, as well as in using communication concepts and skills to teach and learn in myriad professional and personal contexts. Whether they do so intentionally or not, families teach children how to/how not to interact with others. They use verbal and nonverbal communication to do so. Advertisements and entertainment media teach us what to perceive as good/bad, better/worse, desirable/undesirable, and appropriate/inappropriate. Medical professionals and caregivers teach us how to care for our minds and bodies. Leaders in a variety of arenas ranging from the political to the professional to the personal teach us norms and values they believe we should embrace. For these reasons, instructional communication research ought to explore teaching and learning across communication contexts.

This issue highlights three types of manuscripts. Reflective essays are "think pieces" that address thorny issues and propose possible strategies for overcoming them via teaching and learning. Sometimes, these thorny issues manifest in the form of best practices that push the boundaries of traditional conceptions of communication pedagogy. In this issue, you will read reflective and best practice essays ranging from pedagogical challenges spurred by the COVID-19 global pandemic, interpersonal communication anxiety, the imposter syndrome, cultural disparities, and WISER programmatic assessment. In addition, you will read theory-driven empirical research studies on the hidden curriculum in higher education, intrusive teaching, integrative ethics, and professional etiquette.

I was also strategic in implementing a heterogeneous team among editorial assistants and board members. I have no doubt that this issue is far stronger because of the quality of work my editorial team put into it. Dr. Renee Kaufmann, assistant professor at the University of Kentucky, serves as Associate Editor and has done an exceptional job of managing submissions and reviews. Her attention to finding diverse reviewers to serve as experts in manuscript topics and methods afforded me an opportunity to base decisions on a broad set of solid evaluations and recommendations. Also central to achieving synergy are the members of the editorial board who took care to provide thoughtful reviews that helped make those selected for publication stronger. Finally, there could be no finer Editorial Assistant than America L. Edwards, who earned her Master's degree at the University of Central Florida and has started her $\mathrm{PhD}$ coursework at the University of California Santa Barbara. America's attention to detail regarding manuscripts and technological issues has been critical to keeping me on task throughout the process. Truly, the manuscripts you read are a result not just of teamwork but of synergy.

Third, I believe that all professors have a responsibility to mentor junior faculty and students; however, I believe the obligation is even greater for those of us professing to be instructional communication scholar-teachers. We know the value of doing so because this is a major aspect of what we study. With that knowing comes the duty to enact it. We need to "practice what we preach" so to speak. In the words of Olympic gold medal-winning decathlete and trans right activist, Caitlin Jenner, "If you're asking your kids to exercise, then you better do it, too." I was intentional to that end in selecting Dr. Kaufmann, an early to mid-career professional to serve as Associate Editor as a means to facilitate her preparation to become a journal editor herself and Ms. Edwards, a graduate student with aspirations toward the professorate to get "behind the scenes" as a means to gain a broader and deeper understanding of the journal publication processes. I also initiated the practice of "junior editorial board members." For each issue, five doctoral students are provided an opportunity to review manuscripts and learn through the modeling of other reviewers and me (Bandura, 1986). They can compare their suggestions and recommendations to those of scholars that have already established a solid research trajectory, as well 
as from me as they read my synthesis of comments made by all reviewers. In this way, I hope they will begin their tenure-track career with a more intricate understanding of the writing and revising process manuscripts undergo on the way to eventual publication.

As you read the manuscripts in this issue, notice that I invited three prolific scholars to illustrate how far we might go with identifying and addressing thorny issues. Ronald C. Arnett (Duquesne University) encourages us to think about the positive pedagogical consequences that can emerge from how we respond to the current crisis in "Communication Pedagogy: The Coronavirus Pandemic." More specifically, he draws from Bochner \& Ellis (2016) to offer an autoethnographic account of how we may be (or need to be) recalibrating communication pedagogy. In "COVID 19 and the Pedagogy of Culture-Centered Community Radical Democracy: A Response from Aotearoa New Zealand," Mohan J. Dutta, Gayle Moana-Johnson, and Christine Elers (Massey University) challenge us to consider how the CARE (Culture-Centered Approach to Research and Evaluation) Center serves as a resource and model for addressing health disparities by "learning to learn from below" (Spivak, 2012, p. 439) with those living at the margins of the margins (Gramsci, 2005). Finally, Lawrence R. Frey and Emily Loker (University of Colorado Boulder) propose implementing constitutive experiential communication pedagogy to address the thorny problem of teaching students how to manage personal/interpersonal issues competently (Frey \& White, 2012; Giffin \& Patton, 1974). I hope that reading their insightful commentary will cultivate your thoughts to engage in a similar conversation through reflection.

We then offer five empirical research studies that expand theory and research. For example, one study examines what and how we teach in the graduate professional seminar in communication (HoufmannLongtin \& Brann). Another focuses on the strain of increased demands for care labor among faculty (Goode, Denker, Cortese, Carlson, \& Morris). Still another interrogates a relationally-based approach for integrating ethics into existing curricula (Ashby-King \& Boyd). Another explores student uncertainty about addressing professors in emails (Hildenbrand, Perrault, \& Devine). The final research study explores trends in the introductory communication course based on 11 national surveys conducted over the past 60 years (Morreale).

We complete this issue with two best practice and one reflective essay. One proposes an undergraduate proseminar course to accelerate professional socialization (Platt). Another offers project-based learning as a means to help non-majors perceive the relevance of a required general education course in communication (LeBlanc). Finally, we close with a reflective essay addressing perceptions of program assessment as a time-consuming waste of time through WISER assessment (Strawser \& Neuberger).

In summary, we are pleased to share these articles with you and hope that they spur your thinking about how we might use what we do as instructional communication and education scholar-teachers to be a catalyst to-as Mandela puts it—change the world in positive and meaningful ways.

\section{References}

Bandura, A. (1986). Social foundations of thought and action: A social cognitive theory. Prentice Hall. Bochner, A., \& Ellis, C. (2016). Evocative autoethnography: Writing lives and telling stories. Routledge.

Frey, L. R., \& White, A. (2012). Promoting personal, interpersonal, and group growth through positive experiential encounter communication pedagogy. In T. J. Socha \& M. J. Pitts (Eds.), The positive side of interpersonal communication (pp. 297-312). Peter Lang. 
Giffin, K., \& Patton, B. R. (1974). Personal communication in human relations. Merrill. Gramsci, A. (2005). The southern question (Vol. 46). Guernica Editions.

Spivak, G. C. (2012). An aesthetic education in the era of globalization (pp. 335-350). Harvard University Press. 